\title{
Experience in the use of "metaknowledge" of geoecology in the working out of the National Concept Sustainable Development of Russia
}

\author{
Sergey Turkov ${ }^{1 *}$ \\ ${ }^{1}$ FSBMS Computing center of Far-Eastern Branch of RAS, Khabarovsk, Russia
}

\begin{abstract}
Some of the scientific questions and basic methodological regulations, which follows from the practice of using "metaknowledge" of geoecology obtained in the process of research and working out of the National Concept of Sustainable Development of Russia (NCSD), as the official doctrine of its development (1996), presented for discussion. The aim of the study is determination of a special (physically adequate to Nature and Society), information, logical and algorithmically organized subdomain of natural scientific knowledge necessary for a comprehensive idea of the original object of the study: active complicated systems (ACS) of "nature-society" class. The main trend of application of the results obtained is elaboration of automated ("human-machine") systems for planning (support) of optimal management decisions for organizational structures of environmental management at the global, regional and local levels of the planet. A new - "geosystem" - approach to solving the problems of sustainable development ("Sustainable Development", 1995), including the possibility of both external ("technogenic") and internal (or "soft", i.e. restoring the ecological balance) management of the ACS "nature-society" is proposed. In terms of "a new theory of entropy", A. N. Panchenkov (1999) worked out scientific formulations of the following concepts: the system of "nature-society" class, the conflict (in the conditions of "uncertainty"), "metaknowledge" of geoecology, "balance" and "sustainable development", as well as diagrams and formulas for calculation of such states. For practical realization of the NCSD in the country a new and worthy of the XXI century "Industry of Knowledge" should be created, which at the national level should proceed from the formula: "Digital Russia" = ("digital Earth" + "digital economy").
\end{abstract}

\section{Introduction}

From social practice it is known, that at present the main problem for our civilization is the solution of the problem of sustainable economic and social development, both of individual regions, and the planet as a whole (G.X. Brundtland commission, 1967). In 1993 it was first formulated and approved by the world community as "the Concept of Sustainable

\footnotetext{
${ }^{*}$ Corresponding author: slturkov@gmail.com
} 
Development" ("Sustainable Development"; the CSD in the abbreviation of the United Nations, 1995) and adopted by several countries (United States, 1993; Russia three years later) as the official doctrines of their state development [1]; (FZ of the Russian Federation No. 440 of 01.04.1996).

Today, this "Concept" is perceived by all as some common or "hypothetically" acceptable and science-based criterion function of future directions of development of Nature and Society. However, despite the considerable efforts of fundamental science, it is still not clear how to realize it in the current practice of management in the conditions of modern development of territories and communities of different (global, regional, local) levels of the planet organization, how to achieve the goal formulated in it, or at least, to objectively assess the degree of approximation in it? Adopted and mediated by the community practice of using the main propositions of this theory are absent in the world society. All this leads only to descriptive, but not constructive and normative conceptions of the science concerning its practical realization (in the form of GIS and GRID systems, neural networks, "Blockchain", Conflict Resolution Network and all other AItechnologies), and also extremely limits the development of specific modules, models, methods and algorithms to make optimal control decisions.

The main reasons for the lack of methodically and algorithmically unified, complete and specific solution of scientific and applied problems of CSD at the global and national levels are the following:

- general underestimation of the scientific complexity and uncertainty of this "Concept" as such;

- the fact of its extraordinary broad interdisciplinary, interdepartmental and social manifestation;

- functional unity of global, regional and local levels of its impact on complicated natural and social systems;

- absence of methodological (model and algorithmic) generality and completeness of methodology, theory and conceptual apparatus of "noosphere" thinking and ecological consciousness;

- lack of technological (physical and mathematical) ways to explain and formalize the world around us, as well as technical means and methods of their practical implementation.

The system analysis shows that the main limiting factor in the development of CSD is a wrong choice of the main direction of the scientific research in this field of knowledge, including the original paradigm, or "ratio" (from: [2, p.25; 306]). Today it is becoming more and more obvious that such thinking and such position of an official science seriously block the further development of its basic foundations, and the Concept itself obviously demands fundamental theoretical and technological reconsideration. To fulfil the requirements of its scientific decision (objective function: "min" loss of the original natural matter, with "max" socially necessary material benefits), a suggestion is made to use the theory of "noosphere" by V.I. Vernadsky (1933) as a basic element in the present report. Thus, the following well-known classical definition was used: "... on a qualitatively new form of organization that arises from the interaction of nature and society, which is characterized by the relationship of the laws of nature with the laws of thinking and socioeconomic development laws of a society".

\section{Methodology and theory of research}

It is known that after the scientific publications of V.I. Vernadsky on the theory of the biosphere (1926) and further "noosphere" (in the definition of E. Le Roy and P.T. de Chardin, 1927), more than 80 years have passed. But if the first of them was theoretically 
and experimentally confirmed by the works of J. Lovelock and L. Margulis ("Geya hypothesis", the 70-ies of the XX century), the theory of the "noosphere" still remains, although very constructive, but a scientific hypothesis. From the point of view of fundamental science, the current situation (except for the modeling of possible consequences of the "Nuclear winter" in Russia, as well as its assessment in the United States [3]) is quite understandable. Thus, in the field of CSD methodology - these are the attempts of the researchers to use the old paradigm (according to I. Newton - "mechanistic" thinking) in the process of its solution.

NCSD of Russia was being developed in the CC, FEB RAS from 2003 to 2017 [4-9]. The initial materials include the term "noosphere" (according to E. Le Roy and P.T. de Chardin, 1927) and its system (functional) interpretation in the view of the last author: "... noosphere seeks to become a single closed system, where each element individually sees, feels, wishes, suffers as also are the others, and at the same time" [10, p.199] and the theory of V.I. Vernadsky (1933) of the same name. The methodology is based on the modern physical ideas about the world around us (Nature and Society) as a materially closed (according to [11]) system. The latter is logically proved by the fact that "... to think the world is not only to register it, but to give it a form of unity, which it would be deprived of if it were thought" [10, pp. 197-198].

The main research method is a "system" approach, but in its qualitatively new evolutionary - form, or in the direction of its "geosystem" (cybernetic) component. Methodically - this is a way of simultaneous and successive study of the "internal" and "external" management by the processes of functioning and development of active complicated systems (ACS) of the class "nature-society" (state "balance" and "sustainable development"). The general technology of cognition also provides for the implementation of the following commonly accepted in the fundamental science logic scheme: "object" $<=>$ "subject" => "methods of research"; the proposed in "Introduction" criterion function was considered as a complete result of the study for practice. Technologically, this process is organized in the form of a successive transition of logic research from descriptive to constructive and then to normative aspects of the interaction of Nature and Society at all required (from preconditions of the task) levels of global, regional and local environmental management.

The main methods of the research are mathematical apparatus of game theories (GT); game-theoretical modeling; "games with nature" ("Game against Nature"), antagonistic, coalition, cooperative, strategic, etc., required under the terms of setting the objectives of the game, along with the methods of strategic pattern recognition (PR). In modeling, this provides full integration of all available today natural science knowledge, as well as the possibility of computing operations of situational control of ACS "nature-society". As special theories and methods of research, we also used "General theory of systems" by L. Bertalanfi [11] and "infinite nesting of matter" by B. Mandelbrot [12], cybernetics [13], synergetics [14] and the theory of stochastic systems [15], as well as experience and practice in the study of complex branches of knowledge [3].

\section{Results and discussion}

While studying the initial methodological problems of CSD, it was noted that its practical solution is impossible without transition from the process of differentiation of all known currently natural science knowledge about the world around us ("mechanistic" thinking; "object-oriented" approach) to their full integration ("noospheric" thinking; "normative" approach). In other words, fundamental science needs its original scientific paradigm to be changed. Otherwise, the CSD will in principle not have its full theoretical and experimental confirmation. The areas of knowledge that are directly related to solving the problems of 
the CSD are shown in Fig. 1. See also: Fig. 1 in [6]. Variants of three possible phase (information) states of scientific paradigms or scientific theories; [16] and the principle of "correspondence" by N. Bor, 1913.

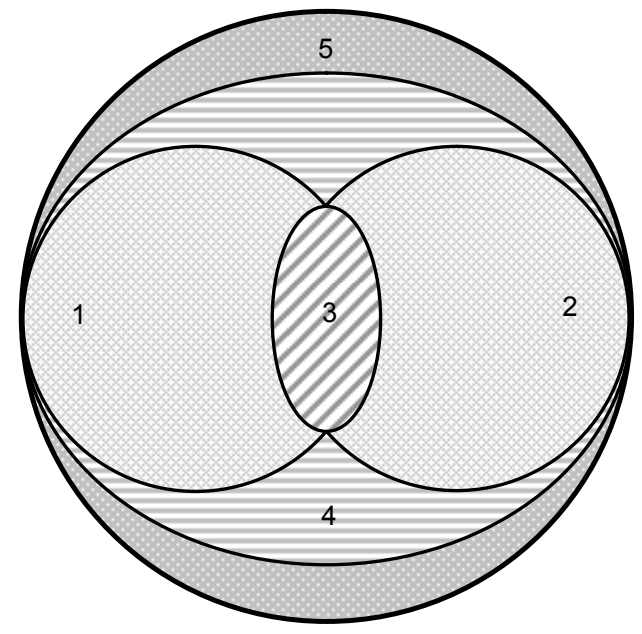

1 - phase space of natural processes; sphere of geographic knowledge

2 - phase space of social (socio-economic) processes; sphere of economic knowledge 3 - natural resources using as interrelated and intersecting processes of nature and society; sphere of knowledge of economic geography and regional economics 4 - physical, chemical and biologic processes of interaction of nature and society; sphere of ecological knowledge 5 - "noosphere" (biosphere) processes of interaction and evolution of the planet geospheres; sphere of knowledge for geoecology

Fig. 1. System conception of the "phase" (information) space of nature management

In the fundamental science, the "thermodynamic" paradigm (according to Newton this is a physical basis of "mechanical" thinking) is known from the second half of the XIX century. But a new - "noosphere" - paradigm being theoretically and experimentally confirmed was developed late in the XX century. It was based on the scientific achievements of the quantum physics (Unified Field Theory, UFT [17], [18]). According to the initial methodology (or ratio, "reasonable beginning, principle, meaning") [2, p. 306]), UFT introduces into natural science in addition to the previously known 4 fundamental interactions the following: gravitational (XYIII century), electromagnetic (XIX century), nuclear (strong and weak, early XX century), and information interactions (late XX century). Thus, it reduces everything exiting in nature to the model: mass $\{M\}$, energy $\{E\}$, information $\{I\}+5$ elementary interactions of their fields. The model was theoretically proved by A. N. Panchenkov in 1999 ("New theory of entropy" [19]). On the basis of the UFT and this theory, in 2017 we developed "Basic physical and information characteristics of modern paradigms of the system conception of the world" (see: [6]; Table. 1, p. 9).

From gnosiology it is known that our thinking about the phenomenon under study a priori should change under changes of the original paradigm, which in its turn should be reduced to a logically and theoretically related, single unit of knowledge, or "metaknowledge" of geoecology. They are logically (theoretically, methodologically, and technologically) higher-level associated knowledge of the object, subject, and problem (target) sub-fields and research methods of each of the complex of sciences on the Earth, Society, and natural science in general, the objective function of which is aimed at the adoption of effective management decisions in the course of their mutual "co-evolution" (N.V. Timofeev-Ressovsky, 1968). At the same time, and in accordance with the logics of our "geosystem" approach as an initial object of study, it is necessary to proceed to the study of active complicated systems (ACS) of the class "nature $<=>$ society". Physically, such systems are mutually integrated systems and objects integrity, the characteristics of which can not be reduced to the properties of the constituent subsystems and are considered as living systems, where the main driving operation and development mechanism is a conflict (in the conditions of uncertainty). "Conflict" in such systems is understood as " ... 
nature's desire to preserve its physical (material-matter), energy and information state as opposed to the human desire to violate it"[4].

Hence (in terms of the "new theory of entropy" of A.N. Panchenkov [19]) the following definitions of the basic concepts of V.I. Vernadsky's "noosphere" theory can be proposed. "Equilibrium " is the state of the ACS "nature $<=>$ society", when in the process of functioning of complicated systems as a whole, the initial position and composition of the structural entropy $\left(\mathrm{H}_{\mathrm{q}}\right)$ are preserved, which include its thermodynamic (or "frozen", $\mathrm{H}_{\mathrm{f}}$ ) part: $\left(\mathrm{H}_{\mathrm{q}} \approx\right.$ const); in this case the "structure-attractor "of the system is relatively stable in "space and time". "Sustainable development" is a state when there are qualitative changes in the structural entropy $\left(\mathrm{H}_{\mathrm{q}}\right.$; it occurs due to "the frozen state", $\mathrm{H}_{\mathrm{f}}$, or thermodynamic entropy: $\left(\mathrm{H}_{\mathrm{q}} \neq\right.$ const $)$; it takes place due to the formation of its new core - the replacement of the old "structure-attractor" by the new one, which will further determine a fundamentally different system, remaining in the future stable in "space and time".

The studies revealed that from the position of the person directly making control decisions (PMD), and in relation to the ACS "nature-society" the general methodology and principal scheme of its actions should have the following form (Fig. 2; using the known principle of "dependence" ("system" + "device") of N. Bor, V. Heisenberg, 1927); development of the control scheme of "teleological" systems from N. Wiener (1950) [13] in the direction of the theory of "noosphere" E. Le Roy, P. T. de Chardin, and V.I. Vernadsky [10].

$\mathrm{H}$

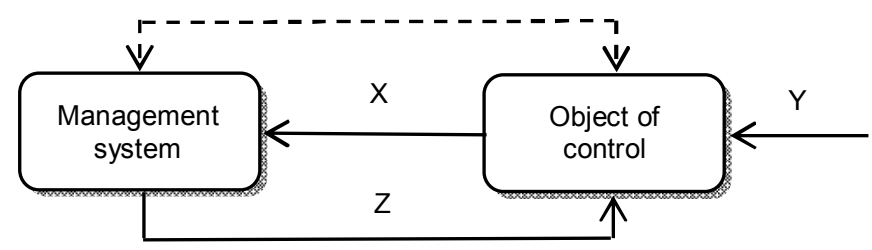

Fig. 2. A general scheme of decision-making under situation management by ACS class "nature-society"

Here the new connection ("H") physically reflects the simultaneous entry of man into the object of control ("object of nature") and the control system (or "subject of nature" - a rational being and a person who has a good chance of making decisions; PMD). This state reveals the "dual" ("biosocial") nature of man (society) and emphasizes its exceptional importance among all other organisms of the biosphere. From here, we can introduce the following general model of ACS management of "nature-society» class:

$$
<\left\{M_{\mathrm{x}}\right\},\left\{M_{\mathrm{y}}\right\},\left\{M_{\mathrm{z}}\right\}, F(f), \varphi, \Psi>,
$$

that is, management is a process of a rational and purposeful making decision, which is determined by a set of states of the control object and the environment $\left(\left\{M_{\mathrm{x}}\right\},\left\{M_{\mathrm{y}}\right\}\right)$, a set of functions of the decision-maker $\left(\left\{M_{\mathrm{z}}\right\}\right)$, acting towards the implementation of the full management function $(\Psi)$, to achieve global and local criteria for optimizing management $(F(f))$, with due regard to the response of the control object to the control impact and environmental influences $(\varphi)$.

Technologically, the optimal control resolution can be achieved by the following methodological procedures. The full matrix of the initial data on the region should be analyzed to special information processing for their compliance to the mathematical apparatus of Games Theory. In case some data (uncertainty) are missing, they are restored by using special methods. Further, their processing by statistical methods allows identification of the data (on the principle of proximity of the "spot" of the regional environmental management process, REMP), situation, which are further to be analyzed more closely by the person making decisions. 
The "balance" of any complex system (if this process is chosen as a final point of the study), is to achieve its so-called "saddle" point (or such its position when the minimum value in the column coincides with the maximum one in the matrix row) [20]. At the same time, the state of "Sustainable development" of such a system in its original sense refers to the field of long-term planning and forecasting problems; for this purpose the concepts of "vogue" and "structure-attractor" are used in the natural sciences and synergetics (all the necessary schemes and formulas for solving such problems are given in [6]).

For science and management (or "control") structures of particular interest are the following computing technologies. These are graphical methods for solving GT problems (Fig. 3), when in real time it is possible to direct visual observation of changes in the schedules of the solution of consistently studied problems (interpretation, diagnosis and monitoring, planning and reconstruction, forecast, situation management).
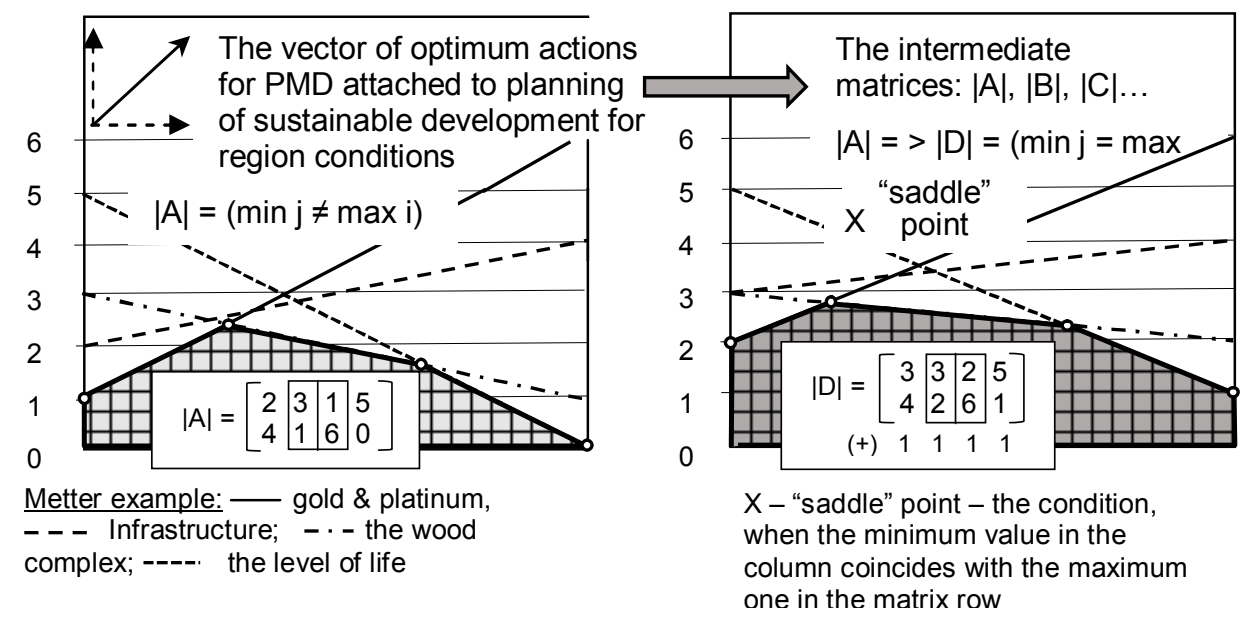

Fig. 3. Graphic scheme of the initial $[\mathrm{A}]$ and output $[\mathrm{D}]$ matrices

Hence it follows that all the situations can be represented as 2- and 3D - dimensional graphs, and their flat reflections (an analogue of the well-known from geography and ecology concept of "Ecological framework of the territory", EFT). Their combination further allows "mixed" GIS-technologies, as well as to Virtual Information Models (VIM) of decision-making: as a result, it is a simultaneous "vector" + "raster" representation of data and knowledge by regions. In addition, according to the well-known from the "Theory of Games" theorem (see: formulas 2.5.22-2.5.24 [20, p. 50-51]) the decision maker can always calculate the values of single optimal strategy and gains from different games and matrices. Then a complete - strategically optimal - solution implies that all data on the "mixed" strategies of all the players are to be obtained (i.e., throughout probability distributions, or shares, their "clean" strategies); this is what all regional management structures should make use of without exception.

\section{Summary}

1. Without methodological transition of contemporary natural science from traditional ("mechanistic") to a new - "noosphere" - thinking, theoretical, technological and methodically correct solution of CSD problems is impossible by definition; this fact is clearly confirmed by many years of negative (scientific and practical) experience of their solution. The suggestion we made of the solution of the problems of the CSD can be based 
on a new subfield of natural scientific knowledge: "Metaknowledge of Earth and Society" (geo-ecology; specialty 25.00.36).

2. When changing the original paradigm a priori should be changed our general scientific thinking and fundamental ideas about the phenomenon studied itself (the principle of "dependence": "system" + "device" by V. Heisenberg, 1927).

3. On the base of the new - "noosphere" - paradigm it is possible to fully fulfill the computational operations of the situational control of the ACS "nature - society" class (deterministic, probabilistic, uncertain and game-theoretical formulation of the control problems).

\section{References}

1. Environmental aspects of the activities of transnational corporations: A surv. N.Y.: UN (1985).

2. Xyojzinga J. Homo ludens. SPb: “Azbuka-klassika” (2007).

3. Moiseev N.N., Aleksandrov V.V., Tarko A.M. A human and biosphere. The knowledge of systems analysis and experiments with models. M.: Nauka (1985).

4. Turkov S.L. The base of control for regional natural resources use. Vladivostok: (2003).

5. Turkov S.L. Decision-making methods in geoecology. MIAB, 4 (2010).

6. Turkov S.L. "Metaknowledge" for geoecology. Prepr. No 225. Khabarovsk: CC FEB RAS (2017).

7. Turkov S.L. Modelling the processes of control for complexity organized "naturesociety" systems // InterCarto/ InterGIS-23. M.: 1 (2017).

8. Turkov S.L. Modelling the processes of control for complexity organized "naturesociety" systems. Europ. Journ. Techn \& Natur. Scien. Vienna-Prague, Austria, 5 (2017).

9. Turkov S.L. The National conception of Sustainable Development for Russia // InterCarto/ InterGIS-24. M.: 1 (2018).

10. Shardin P.T. Fenomen of Human. M: Nauka (1987).

11. The researches by common theory of systems. M.: (1969).

12. Mandel'brot B. Fraktal geometry of nature. ICI (2002).

13. Viner N. Cybernetics or control and connection in animal and machine. M.: Sov. Radio, (1968).

14. Xaken G. Synergetics. M.: Mir (1980).

15. Pugachev V.S., Sinitsy'n I.N. The theory of stochastic systems. M.: Logos (2004).

16. Kuhn T. Structure of Scientific Revolutions. Univ. of Chicago, 2 ed. (1970).

17. Arntz U., Chasse B., Visente M. What the bleep do we know? M.: (2013).

18. Tixoplav T.S., Tixoplav V.Yu. The physics of belief. SPb.: ID "Ves" (2002).

19. Panchenkov A.N. Entropy. N. Novgorod (1999).

20. Ouehn G. Game theory. Ed. LKI (2008). 